\title{
EFFECT OF DEGRADATION ON MULTISPECTRAL SATELLITE IMAGE
}

\author{
"Salah A. Saleh, ** Nihad A. Karam, and ${ }^{* *}$ Mohammed I. Abd Al-Majied \\ "College of Science, University of Al-Nahrain. \\ ** Department of Astronomy, College of Science, University of Baghdad.
}

\begin{abstract}
Satellite images record electromagnetic radiation intensity that emitted or reflected from Earth's object within the field of view (FOV) of satellites sensor. These radiations are affected by the turbulent atmosphere and other effects (like noise and motion detectors), thus will reduce the quality of acquired images.

The degree of distortion depends on wavelength, and since satellite images are taken in different wavelengths (multispectral bands) including visible and infrared (emitted and reflected). So, each band of satellite images will have different value of distortion.

In this work, computer program (using matlab language) has been written to study the degradation effect parameters for each band of Landsat7 satellite image. The main objective is to show which band has less effect. It is found that band3 $(0.630-0.690 \mu \mathrm{m})$, band4 $(0.750-0.900 \mu \mathrm{m})$ and band7 (3.090-2.350 $\mu \mathrm{m})$ has great atmospheric effect for vegetation, water and sand area respectively. Archive of these areas is build up to estimated parameters used for recovery other images. Result shows that when the size of the recovered area is small best results are obtained from it.
\end{abstract}

\section{Introduction}

Satellite images are often recorded under a wide variety of circumstance. As imaging technology is rapidly advancing. Since our technology is not perfect, every recorded satellite image is a degraded version of the scene in some sense. Every imaging system has a limit to its available resolution and the speed at which images can be recorded.

Some unusual sensory abilities are present in natural world, such as the ability to detect magnetic and electric fields, or the use of ultrasound waves to determine the structure of surrounding obstacles [1].

The current understanding about the nature of light and color can be traced to the work of the Sir Isaac Newton. The light is characterized physically by its spectral composition [2].

Multispectral imaging entails acquiring several images of the same scene using different spectral bands [3]. Collecting several spectral bands generally provides more information than would be obtained from a single monochrome image. This idea has been applied in the field of remote sensing for over 20 years. Landsat Earth observation satellites are capable of acquiring multispectral bands spanning visible and non-visible wavelengths such as infra-red. The full set can be processed to identify different kinds of land use automatically [3]. The former type of data collection can be accomplished by different sensors operating simultaneously (multisensor) or by a single sensor that operates in several spectral regions simultaneously (multispectral or multiband sensor) [4].

\section{Theory}

The degradation process model consists of two parts, the blurring function and the noise function. The general formation model in the spatial domain is given by [5]:

$$
\mathrm{g}(\mathrm{x}, \mathrm{y})=\mathrm{h}(\mathrm{x}, \mathrm{y}) \otimes \mathrm{f}(\mathrm{x}, \mathrm{y})+\mathrm{n}(\mathrm{x}, \mathrm{y}) \ldots(1)
$$

Where

$\otimes$ denotes the convolution process

$g(x, y)=$ degraded image.

$h(x, y)=$ blurring function

$f(x, y)=$ original image

$n(x, y)=$ additive noise function

Because convolution in the spatial domain is equivalent to multiplication in the frequency domain, the frequency model is [5]: 


$$
\mathrm{G}(\mathrm{u}, \mathrm{v})=\mathrm{H}(\mathrm{u}, \mathrm{v}) \mathrm{F}(\mathrm{u}, \mathrm{v})+\mathrm{N}(\mathrm{u}, \mathrm{v}) \ldots \ldots .(2)
$$

Where

$$
\begin{aligned}
& G(u, v)=\text { Fourier transform of the } \\
& H(u, v)=\text { Fourier transform of the }
\end{aligned}
$$

In the terminology of linear system theory, the transform $H(u, v)$ is called the transfer function of the process. In optics, $H(u, v)$ is called the optical transfer function, and its magnitude is called the modulation transfer function [6].

This Function represents the most operative image degradation. It determines the energy distribution in the image plane due to point source located on the object plane [7].

Blur model can categorized into two types: 1-space-invariant point spread function (SIPSF).

2-space-variant point spread function (SVPSF).

The most causes of it are:

\section{i. Turbulence of atmosphere:}

The electromagnetic radiation travels through empty space without modification, a series of diversions and depletions occurs as solar and terrestrial radiation interacts with the Earth's atmosphere. This interference is wavelength selective, meaning that electromagnetic radiation (EMR) at certain wavelengths passes freely through the atmosphere, where as it is restricted at other wavelengths [4].The refractive index of the Earth's atmosphere varies over space and time. The dependence on temperature, $T$, and pressure, $p$, of the refractive index of air is given by [8]:

$$
\mathrm{n}=1+77.6\left(1+7.52 * 10^{-3} \lambda^{-2}\right) \mathrm{p} / \mathrm{T} * 10^{-6}
$$

\section{ii. Aberration:}

The aberration can be defined as the departure or deviation from the laws of Gaussian (paraxial) image formation [9].

\section{iii. Motions blur:}

It is the appearing streaking of rapidly moving objects in a still image or a sequence of images such as movie or animation [10].
The other one noise represents any undesired information that contaminates an image [5]. It can be modeled with a Gaussian ("normal"):

$$
\text { Histogram }_{\text {Gaussian }}=\frac{1}{\sqrt{2 \pi \sigma^{2}}} \mathrm{e}^{-(\mathrm{g}-\mathrm{m})^{2} / 2 \sigma^{2}}
$$

Where

$$
\begin{aligned}
& g=\text { gray level } \\
& m=\text { mean (average) } \\
& \sigma=\text { standard deviation }\left(\sigma^{2}=\text { variance }\right)
\end{aligned}
$$

There are two types of noise: [11]
a. Additive noise.
b. Multiplicative noise.

The most noise sources are:

\section{i. Photon noise:}

When the observed physical signal is based upon light, the quantum nature of light plays a significant role [12].

\section{ii. Sky noise:}

Sky noise refers to fluctuations in total power or phase of a detector caused by variations in atmosphere emissivity and path length on timescales of order one second [13].

\section{iii. Instrument noise:}

The source of noise in general is divided into photochemical and photoelectric effect [14][15].

\section{Simulation and Results}

In this work it is particular interested in applying statistical methods to obtain a quantitative estimation to the degradation. In the first stage, the comparison between the original and the degraded bands have been executed so as to show which band is less degraded from all bands.

The study cases used in this work; taking image using following bands, band1 $(\lambda=0.450-0.515 \mu \mathrm{m}), \quad$ band $2 \quad(\lambda=0.525-$ $0.605 \mu \mathrm{m})$, band3 $(\lambda=0.630-0.690 \mu \mathrm{m})$, band4 $(\lambda=0.750-0.900 \mu \mathrm{m}), \quad$ band5 $\quad(\lambda=1.550-$ $1.750 \mu \mathrm{m})$, and band7 $(\lambda=3.090-2.350 \mu \mathrm{m})$ from landsat7 are used. The atmospheric turbulence can be represented by Gaussian blur function and Gaussian additive noise with mean equal to zero. Vegetation, water and sand window of size $(9 * 9)$ pixels cropped from multispectral images shown in Fig. (1) 
which is the west of Iraq. These areas are divided into single bands and being utilized in our program. The value of the $\left(\sigma_{\text {Blur }}\right)$ of Gaussian blur function is (1-20) and for $\left(\sigma_{\text {Noise }}\right)$ of Gaussian additive noise is $(0,0.015$, 0.030). The cross correlation coefficient is taken between affected and original image. Fig. (2) to Fig. (10) showing the result.

In the second stage, library of simple images area (vegetation, water and sand area) which is established is used for estimating the parameter of degradation. This archive is of size $(9 * 9)$. These samples are degraded with $\left(\sigma_{\text {Blur }}=1-20\right)$ and $\left(\sigma_{\text {Noise }}=0,0.010\right.$, $0.015,0.020,0.025,0.030)$. From the figures Fig. (2) to Fig. (10) shown before. The less degraded bands are denoted and used in this archive. These resulted parameters are used in the Wiener filter to recover area of new images. These images are tested in the archive after degraded by Gaussian function $\left(\sigma_{\text {Blur }}=2,4,8\right)$ and Gaussian additive noise $\left(\sigma_{\text {Noise }}=0.005,0.010\right)$.

Fig. (11a) and Fig. (11b) is the image of the desert around the Salton Sea and Imperial Valley in southern California. Fig. (11a) and Fig. (11b) are been corrected by the bilinear interpolation method. Fig. (11c) and Fig. (11d) encompassing the region from long beach to San Diego and also of southern California.

The result is showing by cross correlation coefficient between the restore one by estimate parameter and with the original parameters in Fig. (12) to Fig. (17).

\section{Conclusions}

The final results that could be derived from this research are:

1. Bands of multispectral images degraded in different degrees. For the water area band 4 $(\lambda=0.750-0.900) \mu m$ is the less degraded one especially for $\left(\sigma_{\text {Blur }}=1-10\right)$ and ( $\left.\sigma_{\text {Noise }}=0,0.015\right)$ as in Fig. (5) to Fig. (7). Band3 $(\lambda=0.630-0.690) \mu m$ is the unaffected one for the vegetation area as in Fig. (2) to Fig. (4). The better of it is at $\left(\sigma_{\text {Blur }}=2-16\right)$. If $\left(\sigma_{\text {Noise }}=0.015,0.030\right)$ great distortion can be seen. Band7 $(\lambda=3.090-2.350) \mu m$ is suitable for the sand area as in Fig. (8) to Fig. (10) particularly when $\left(\sigma_{\text {Blur }}=1-18\right)$ and $\left(\sigma_{\text {Noise }}=0\right)$.

2. Band4 $(\lambda=0.750-0.900) \mu m$ and band7 $(\lambda=3.090-2.350) \mu m$ are not affected by atmospheric haze because the large wavelength of them. The reflectance of band5 $(\lambda=1.550-1.750) \mu m$ is decreases especially when pass through water or water vapor because it is absorbed by it.

3. Band3 ( $\lambda=0.630-0.690) \mu m$ is sensible to strong chlorophyll absorption region and it is the best one for discriminating vegetation area from soils.

Good approximation for the estimation parameter as compared to the restoration with the original degradation parameter is obtained.

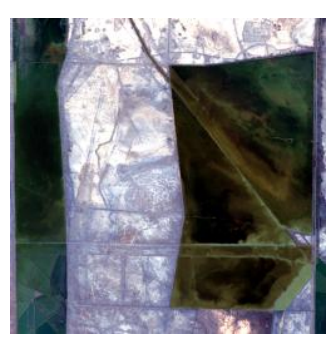

(a)

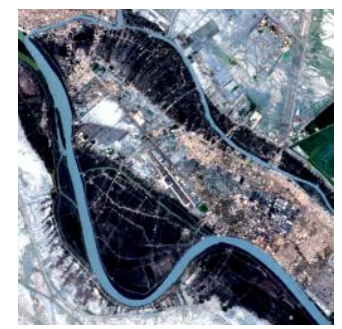

(c)

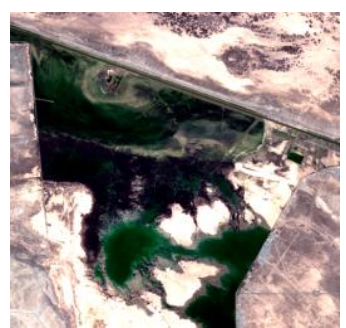

(e)

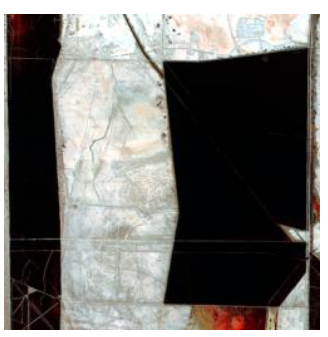

(b)

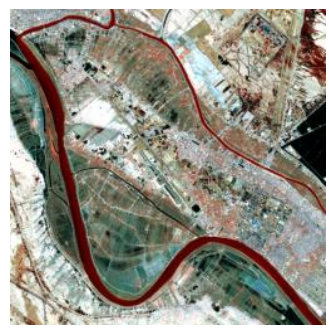

(d)

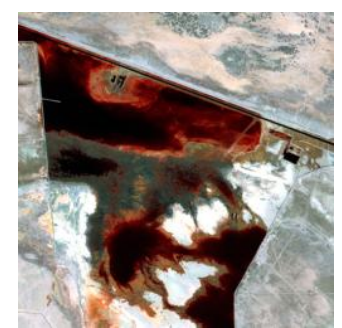

(f)
Fig. (1) : Images of mltispectral of size $(512 * 512)$ from Landsat 7 . 


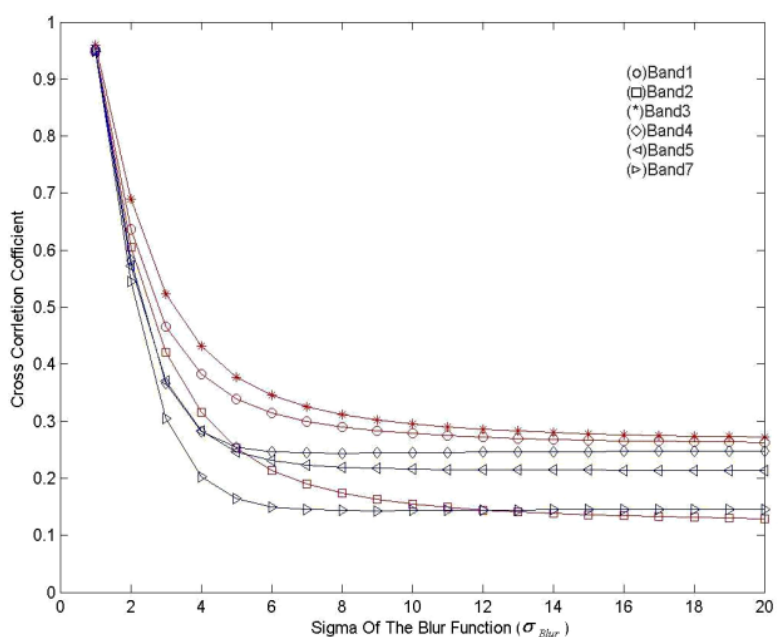

Fig. (2) : Cross correlation coefficient for case when $\left(\sigma_{\text {libise }}\right)=0$ for area $(\mathbf{a}),(\mathbf{b})$ (vegetation).

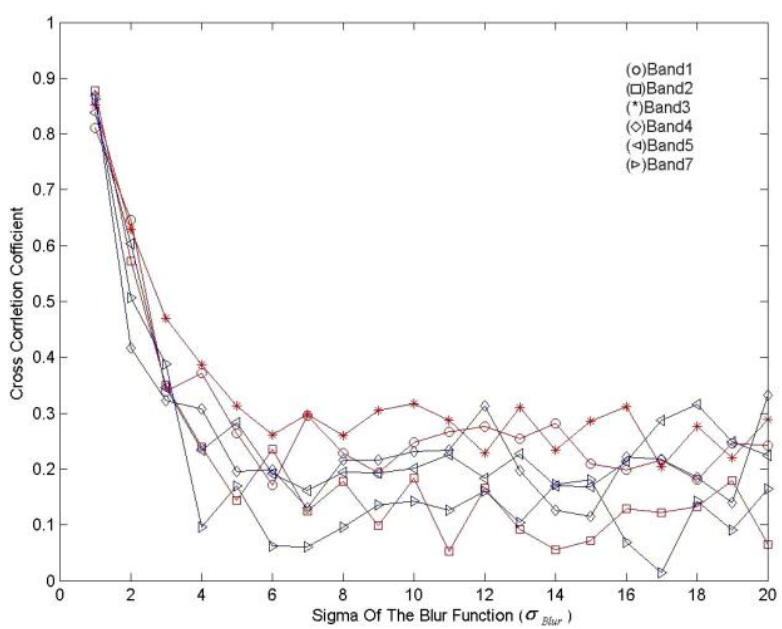

Fig. (3) : Cross correlation coefficient for case when $\left(\sigma_{\text {ibise }}\right)=0.015$ for $\operatorname{area}(\mathbf{a}),(\mathbf{b})$ (vegetation).

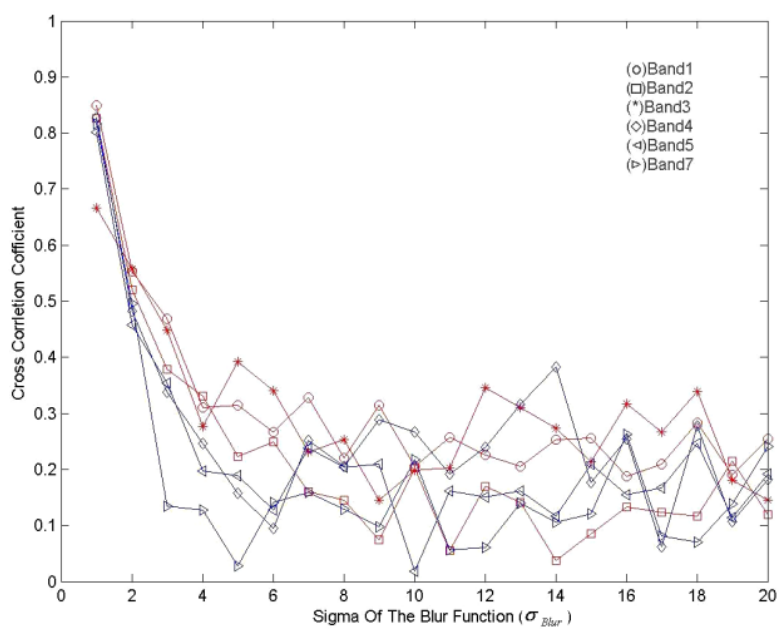

Fig. (4) : Cross correlation coefficient for case when $\left(\sigma_{\text {ibise }}\right)=0.030$ for area $(\mathbf{a})$, (b) (vegetation).

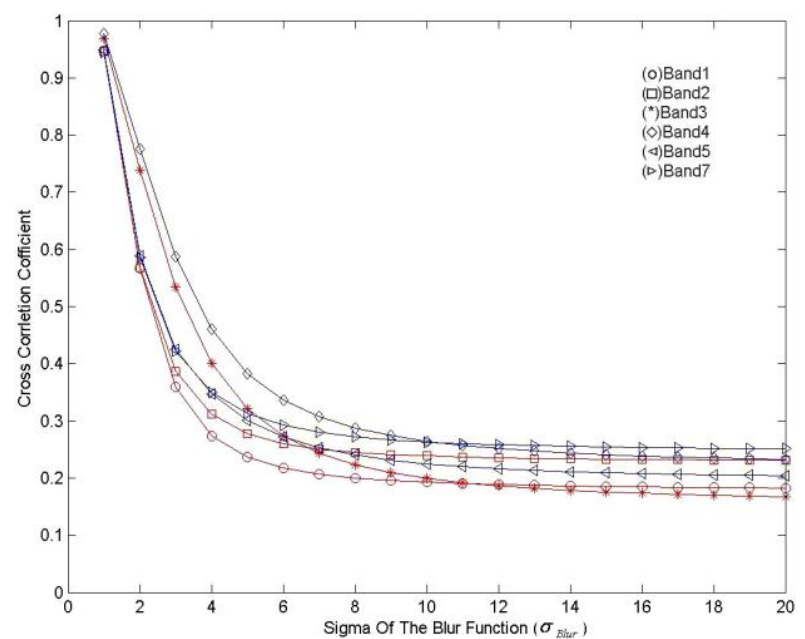

Fig. (5) : Cross correlation coefficient of case when $\left(\sigma_{\text {Noise }}\right)=0$ for area $(\mathbf{c}),(\mathbf{d})$ (water).

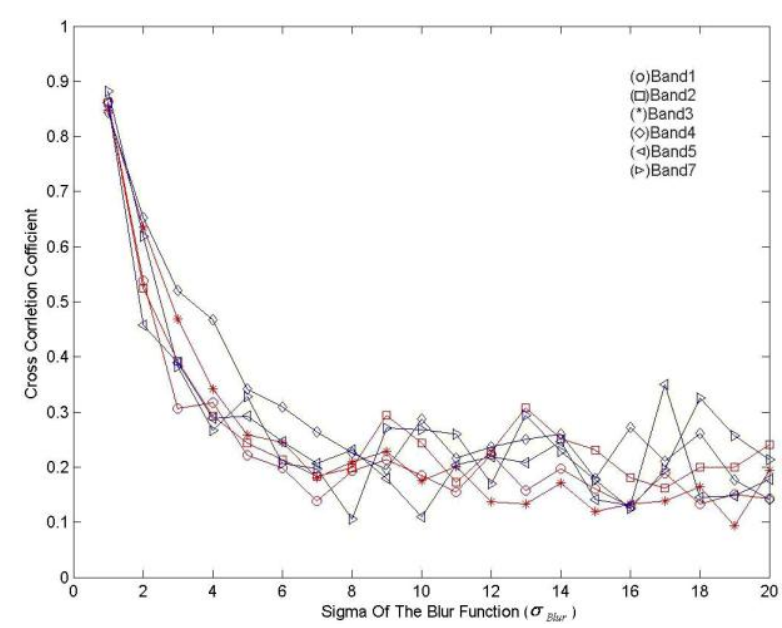

Fig. (6) : Cross correlation coefficient for case when $\left(\sigma_{\text {Rioise }}\right)=0.015$ for area $(\mathbf{c}),(\mathrm{d})$ (water).

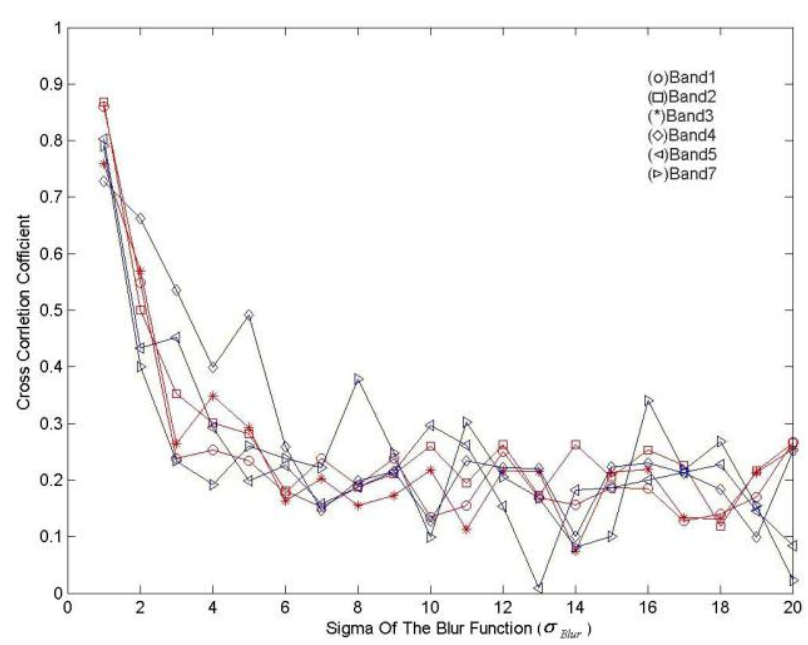

Fig. (7) : Cross correlation coefficient for case when $\left(\sigma_{\text {ikise }}\right)=\mathbf{0 . 0 3 0}$ for $\operatorname{area}(\mathbf{c}),(\mathrm{d})$ (water). 


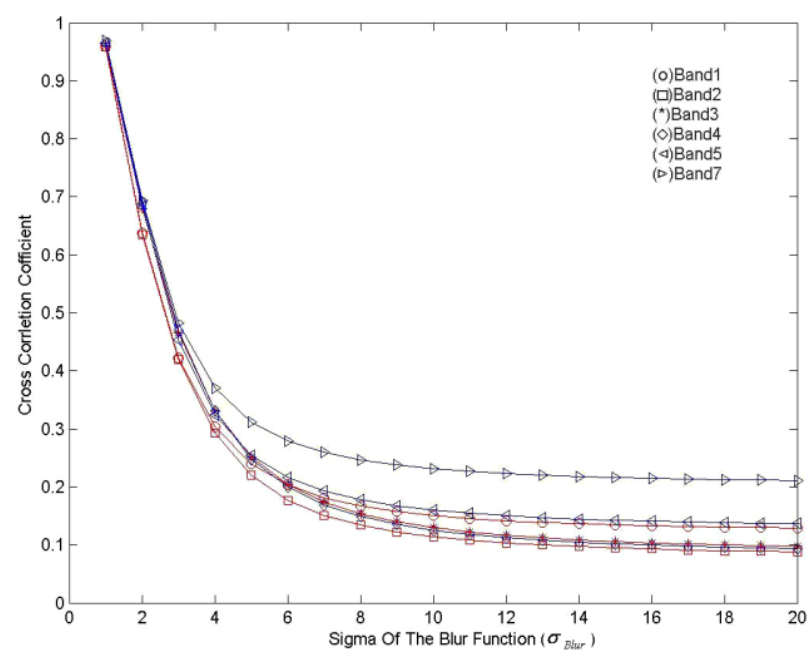

Fig. (8) : Cross correlation coefficient for case when $\left(\sigma_{\text {Iioise }}\right)=0$ for ar ea (e), (f) (sand).

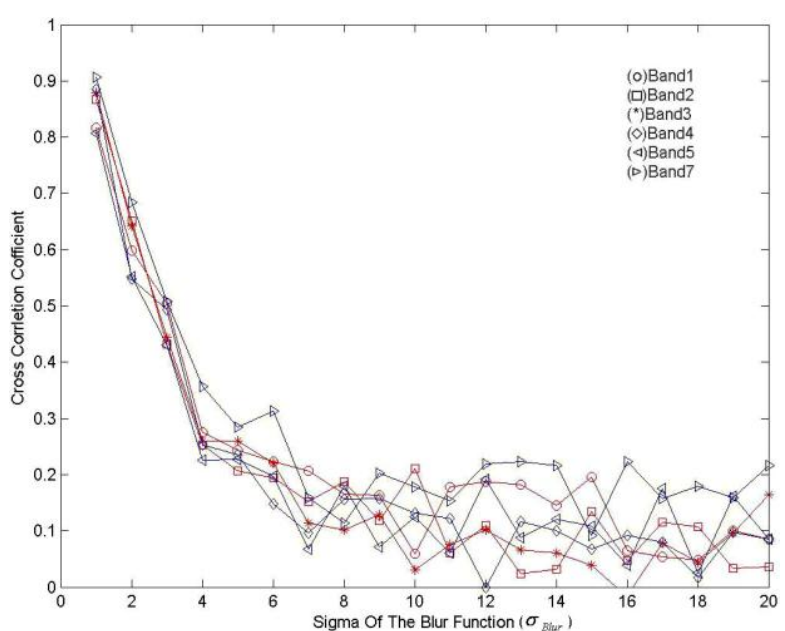

Fig. (9) : Cross correlation coefficient for case when $\left(\sigma_{\text {Noise }}\right)=0.015$ for $\operatorname{area}(\mathrm{e}),(\mathrm{f})$ (sand).

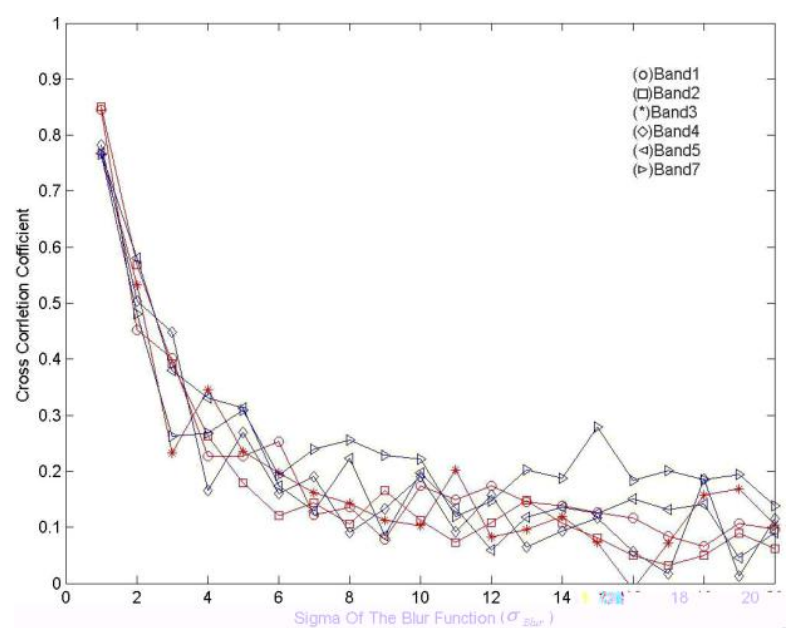

Fig. (10) : Cross correlation coefficient for case when $\sigma_{\text {libise }}=\mathbf{0 . 0 3 0}$ for area $(\mathbf{e})$, (f) (sand). (a)

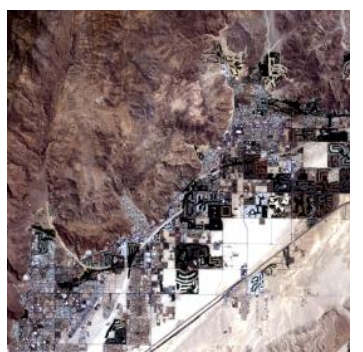

(c)

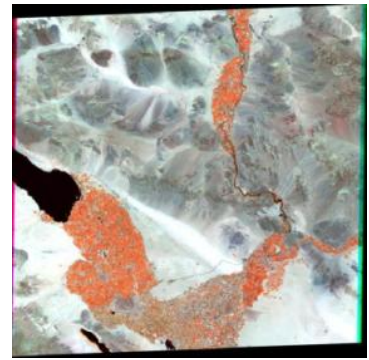

(b)

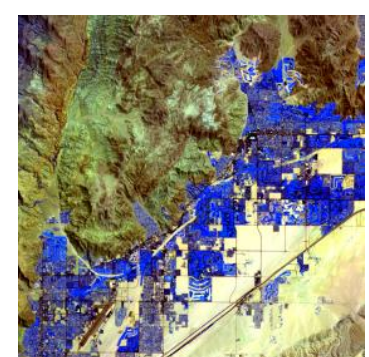

(d)
Fig. (11) : Images of multispectral of size $(512 * 512)$ from Landsat7. 


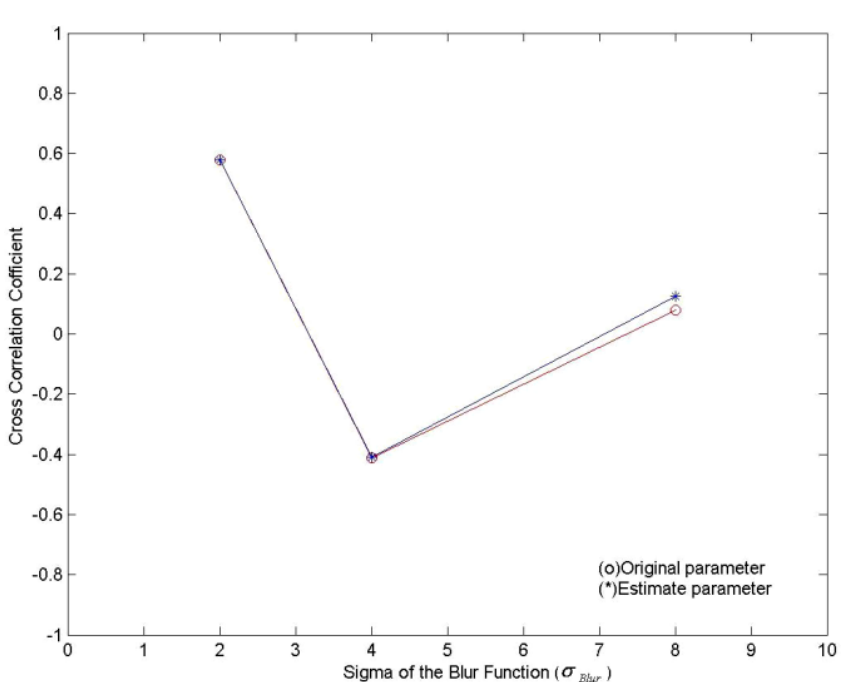

(a)

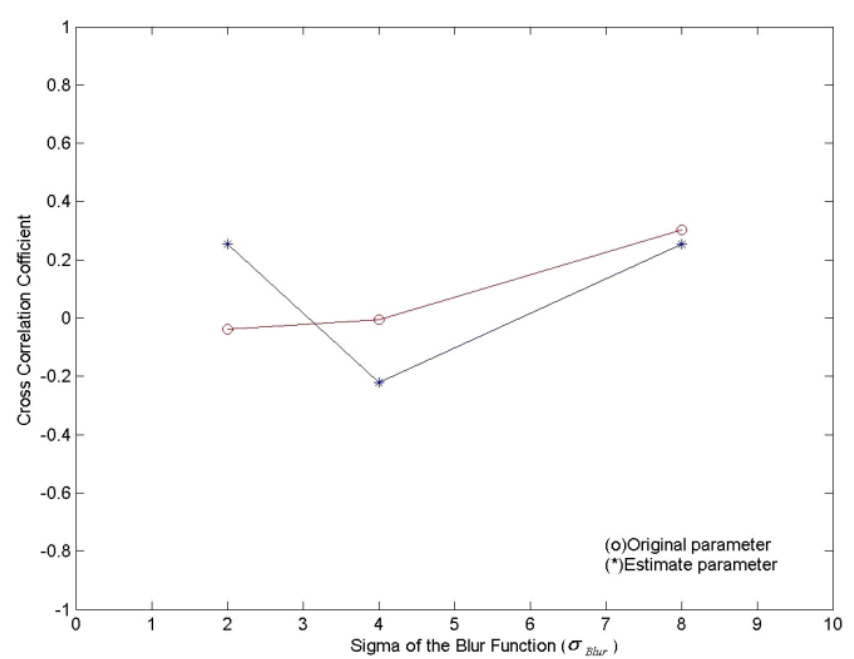

(b)

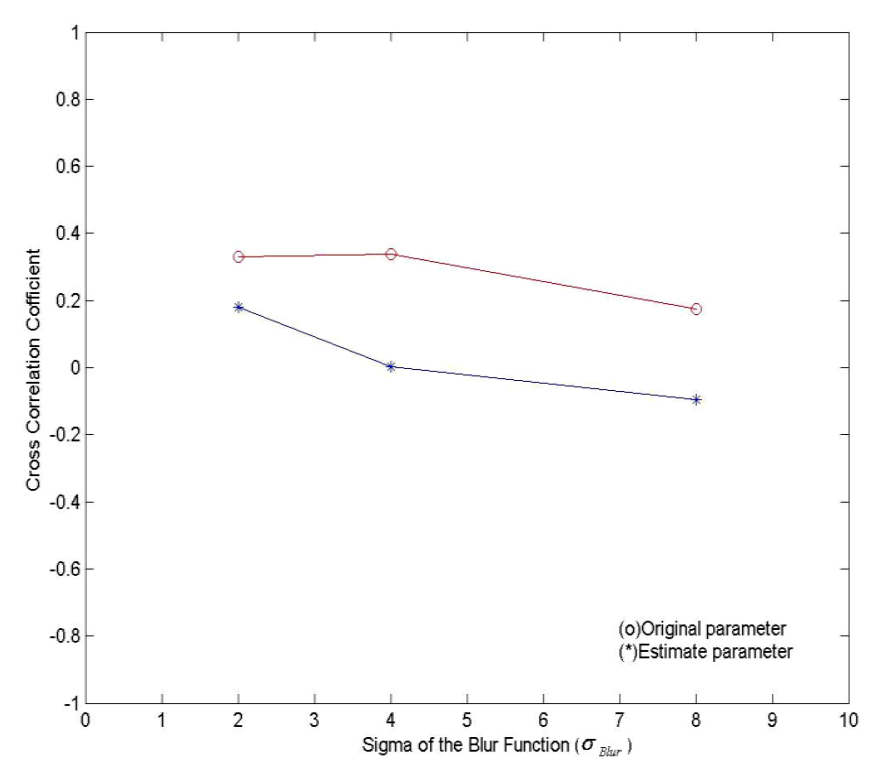

(c)

Fig. (12) : Cross correlation when the size of area (a) $(3 * 3),(b)(6 * 6),(c)$ $(9 * 9)$, with $\left(\sigma_{\text {Noise }}=\mathbf{0 . 0 0 5}\right)$.

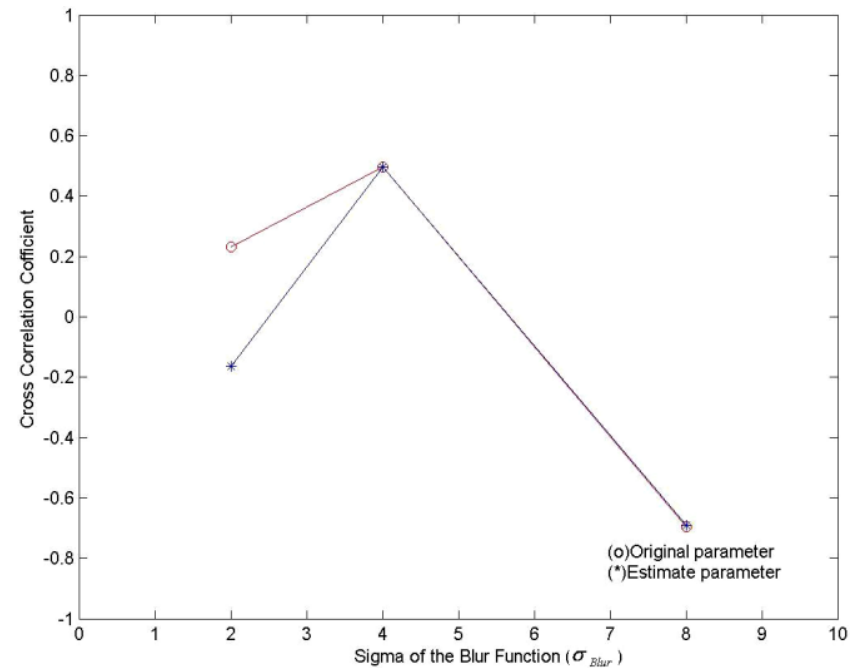

(a)

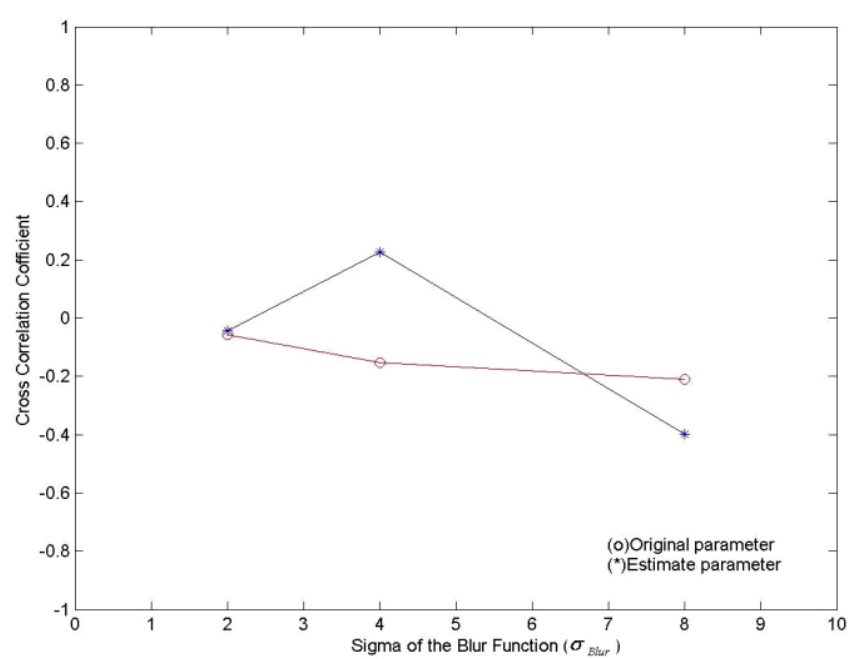

(b)

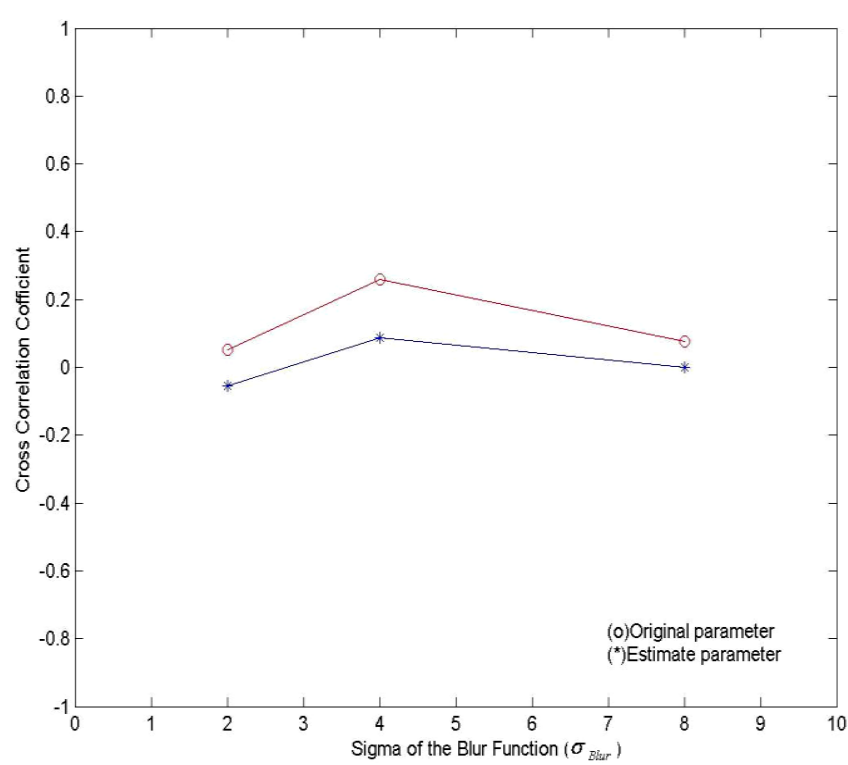

(c)

Fig. (13) : Cross correlation when the size of area (a) $(3 * 3),(b)(6 * 6),(c)$ $(9 * 9)$, with ( $\left.\sigma_{\text {Noise }}=\mathbf{0 . 0 1 0}\right)$. 


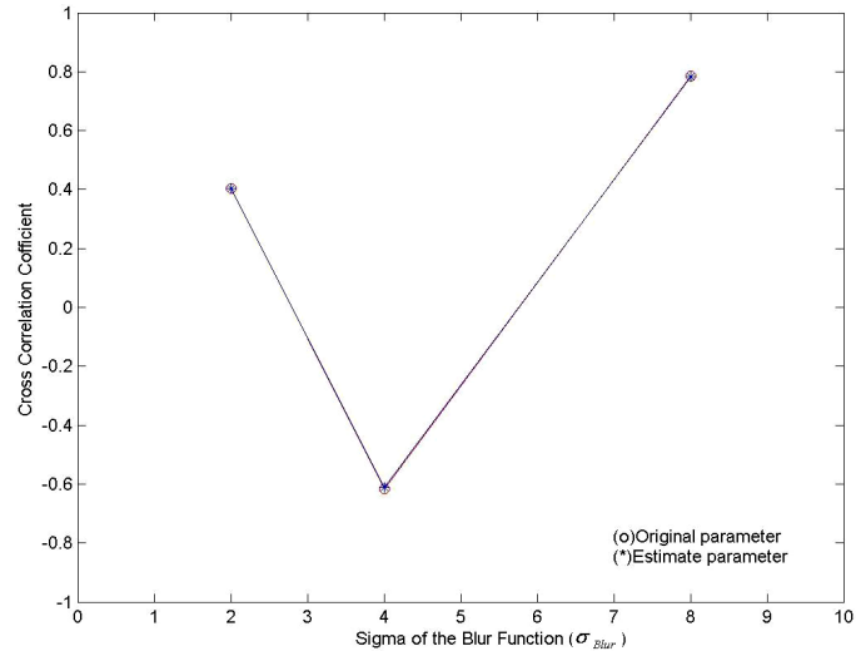

(a)

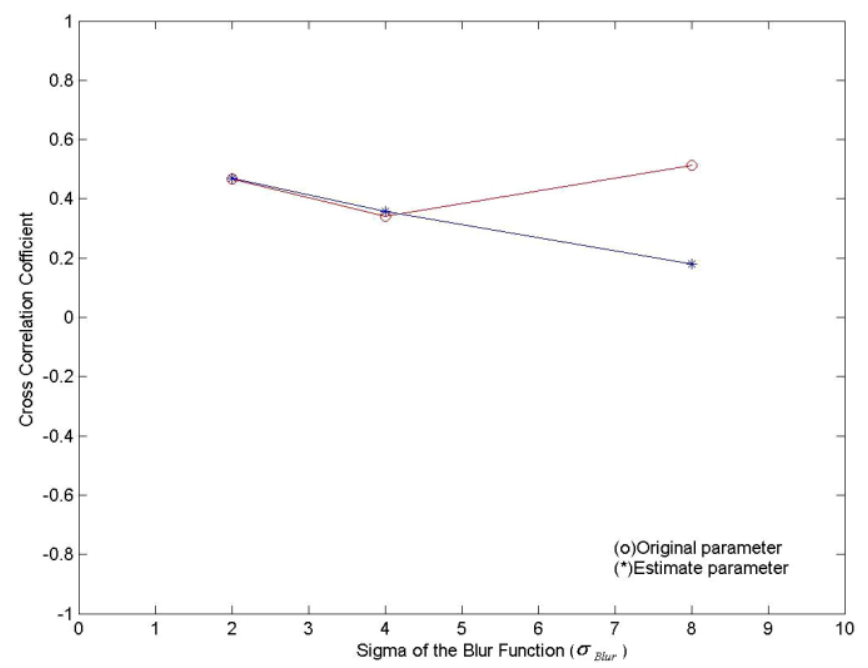

(b)

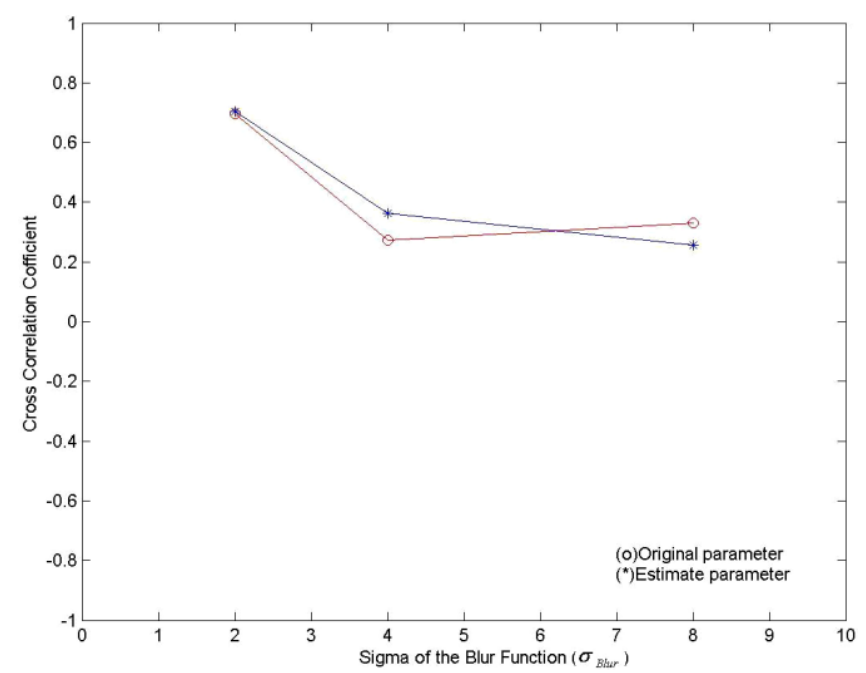

(c)

Fig. (14): Cross correlation when the size of area (a) $(3 * 3),(b)(6 * 6),(c)$ $(9 * 9)$, with $\left(\sigma_{\text {Noise }}=\mathbf{0 . 0 0 5}\right)$.

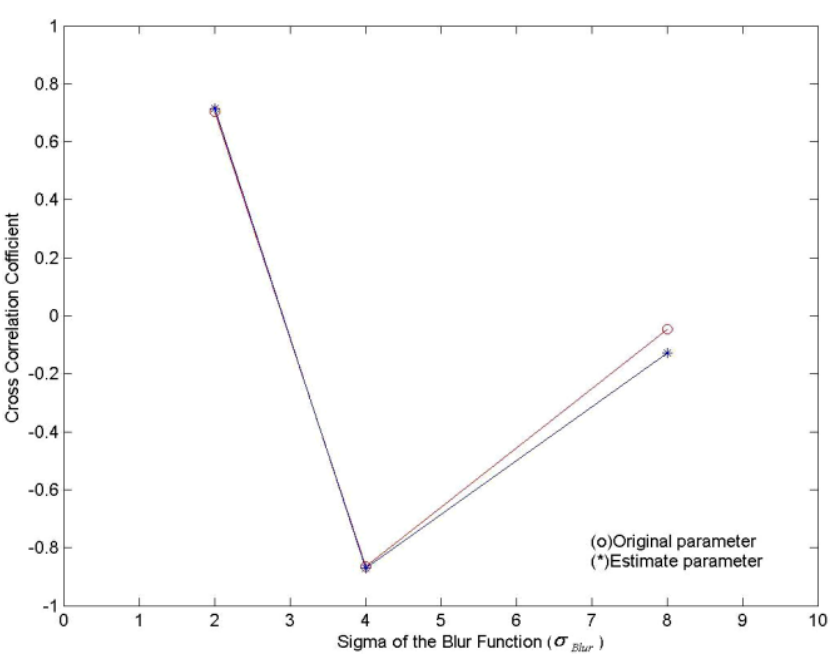

(a)

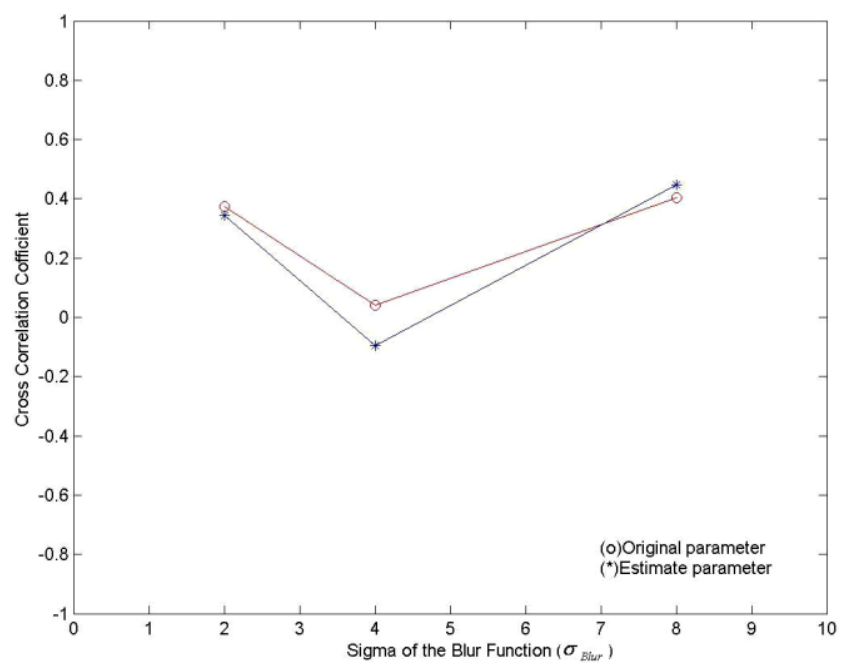

(b)

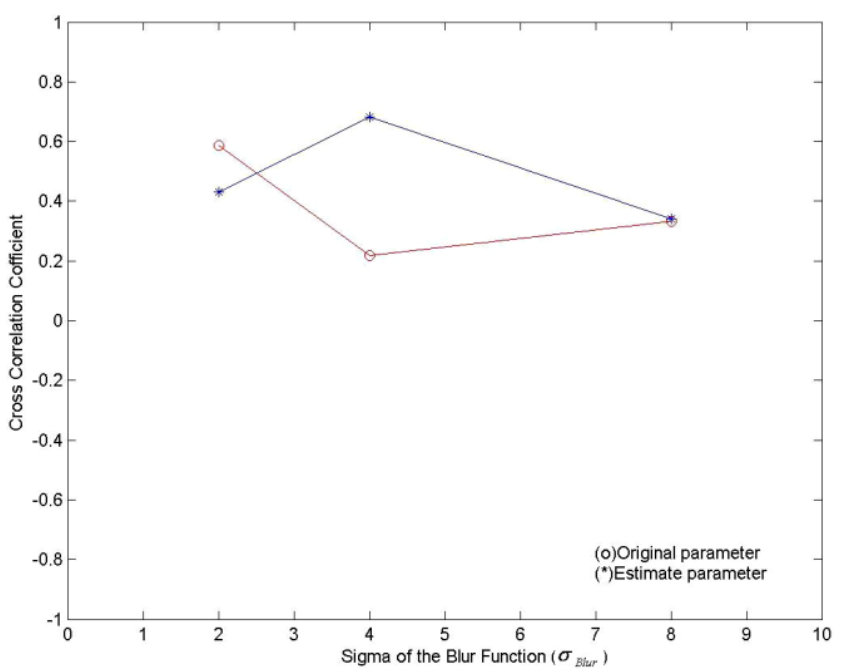

(c)

Fig. (15) :Cross correlation when the size of area (a) $(3 * 3),(b)(6 * 6),(c)$ $(9 * 9)$, with $\left(\sigma_{\text {Noise }}=\mathbf{0 . 0 1 0}\right)$. 


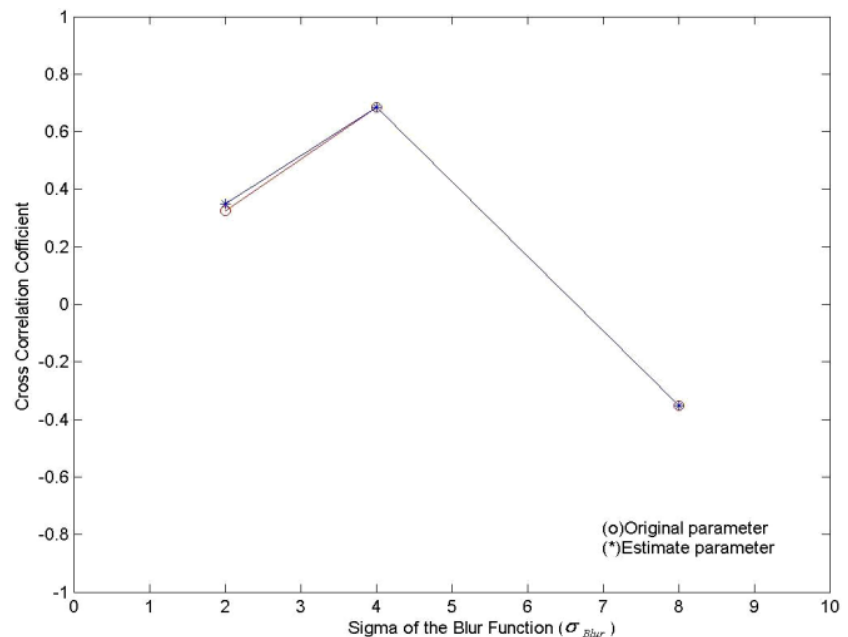

(a)

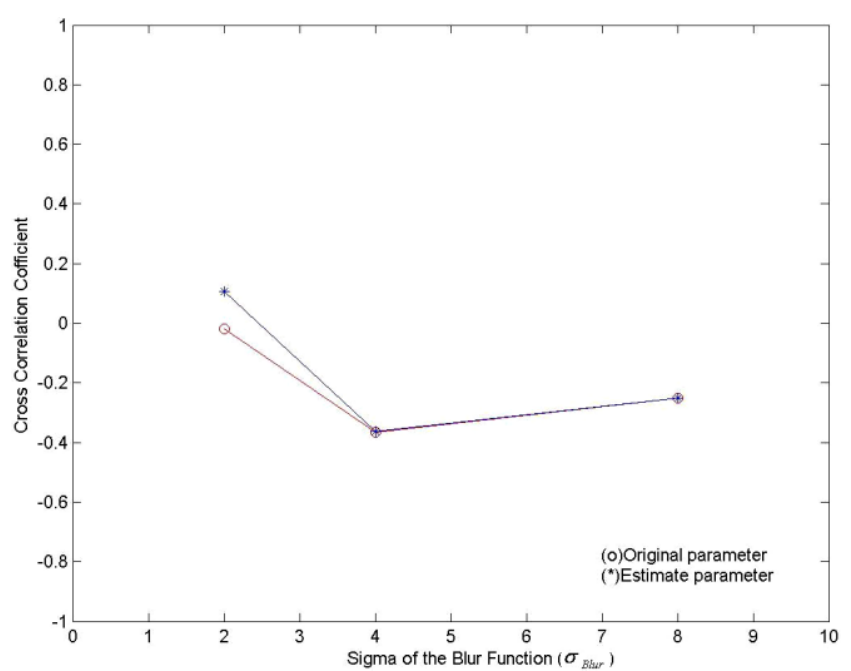

(b)

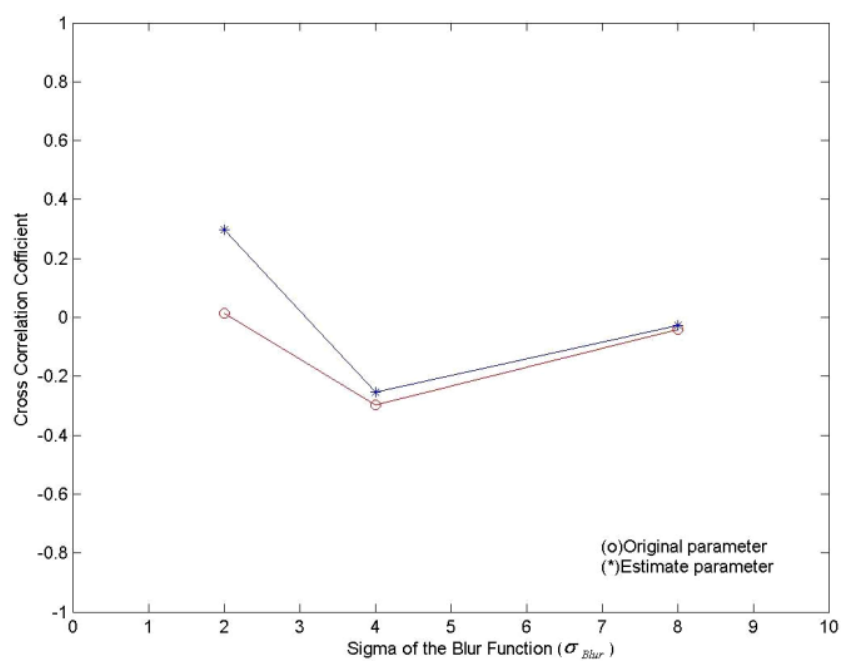

(c)

Fig. (16) : Cross correlation when the size of area (a) $(3 * 3),(b)(6 * 6),(c)$ $(9 * 9)$, with $\left(\sigma_{\text {Noise }}=\mathbf{0 . 0 0 5}\right)$.

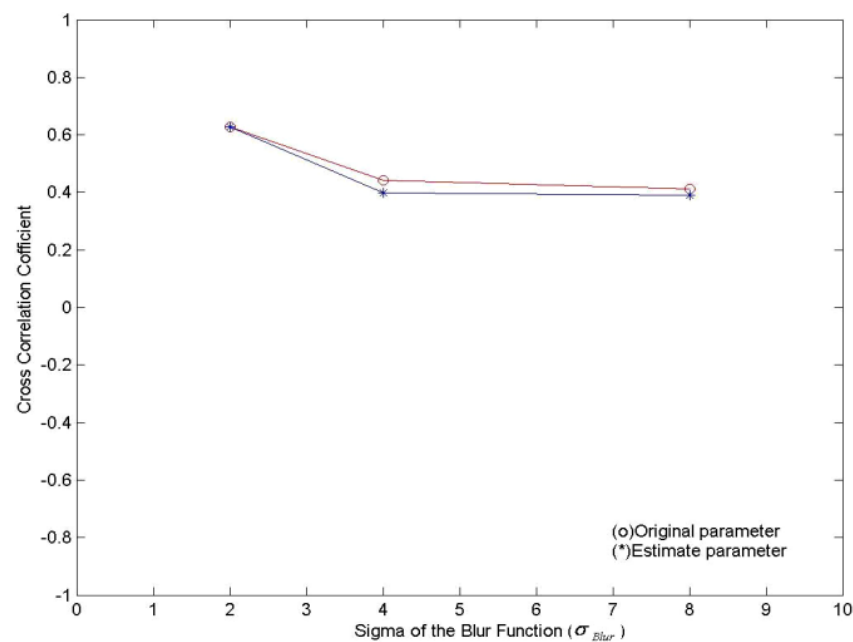

(a)

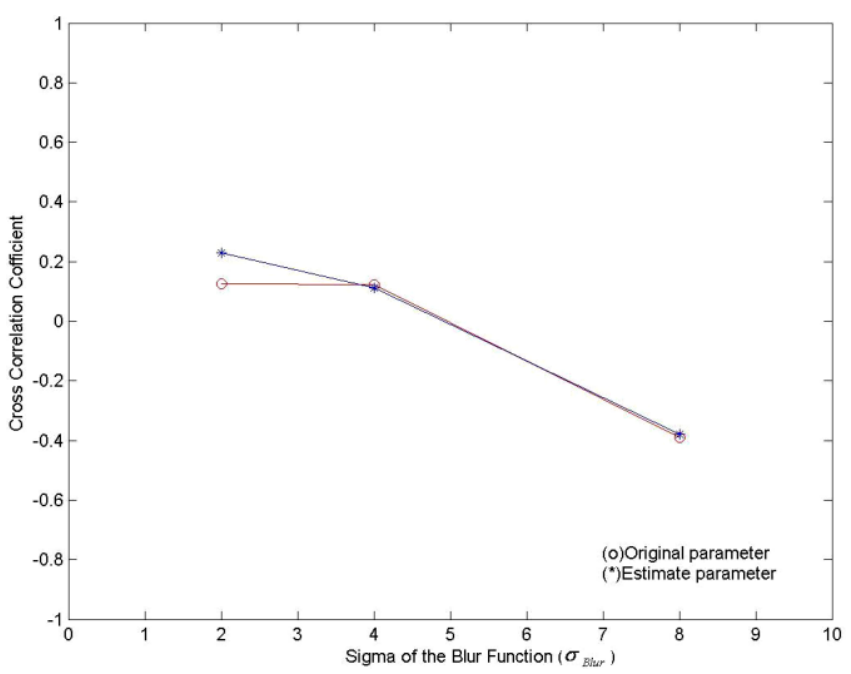

(b)

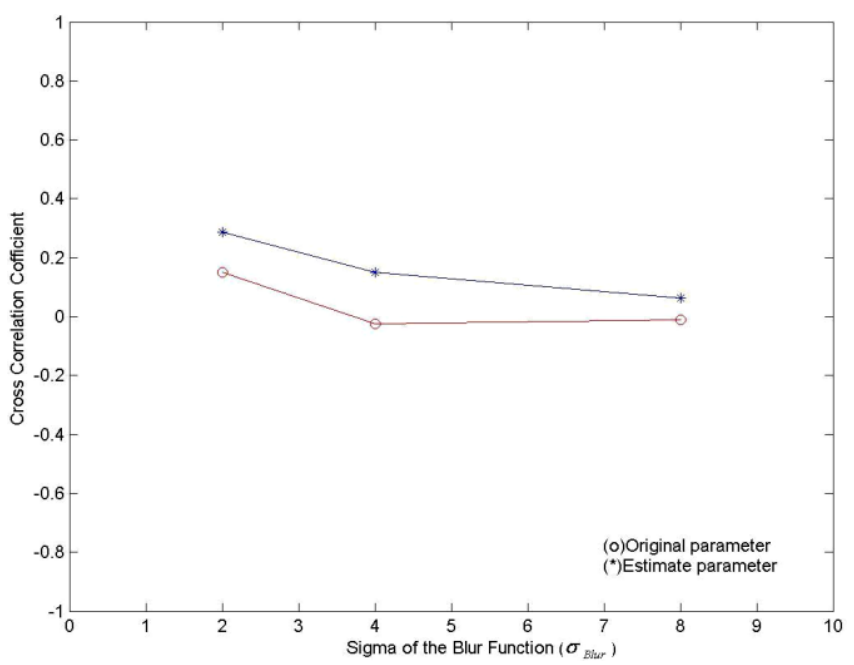

(c)

Fig. (17) : Cross correlation when the size of area (a) $(3 * 3)$, (b) $(6 * 6)$, (c) $(9 * 9)$, with $\left(\sigma_{\text {Noise }}=\mathbf{0 . 0 1 0}\right)$. 


\section{References}

[1] S. Perry, H. Wang and L. Guan, "Adaptive Image Processing", CRC Press LLC, (2002).

[2] G. Sharma, "Digital Color Imaging", CRC Press LLC, (2003).

[3] "Deep Multispectral Image Processing". (2002).www.cs.kent.ac.uk/people/stafl/pg k/DeepMultispctral .html.

[4] T. Avery and G. Berlin, "Fundamentals of Remote Sensing and AirPhoto Interpretation", Prentic-Hall (1992).

[5] S. Umbugh, "Computer Vision and Image Processing", Printice Hall PTR, (1998).

[6] R. Gonzales and R. Woods:" Digital Image Processing", Fifth ed., Pearson Education Asia Pte Ltd (2000).

[7] J. Goodman, "Introduction to Fourier Optics", Megraw-Hill, New York (1968).

[8] J. Goodman, "Statistical Optics", Johan Wily and Sons (1984).

[9] F. Hecht and A. Zajac, "Optics", A. W. W. S, (1974).

[10] "Motion Blur", (2006). en.wikipedia.org/wiki/Motion-blur.

[11] A. Jain, "Fundemental of Digital Image Processing", Prentice Hall, pp 244-253, 273-275, (1989)."Photon Noise", (2006). www.ph.tn.tndelft.nl/Courses/FIP/nofra mes/fip-photon.html.

[12] "Sky Noise", (2002). Photo noise.

[13] www. harvard. Edu/ aas/tenmeter/noise. htm.

[14] B. Hunt, Proc IEEE, vol. 63, pp. 693(1975).

[15] H. Anderws and B. Hunt, "Digital Image Restoration", Prentic-Hall-New Jersy (1977).

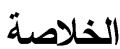

$$
\begin{aligned}
& \text { تسجل صور الأقمار الصناعيه الخاصه بالأستشعار }
\end{aligned}
$$

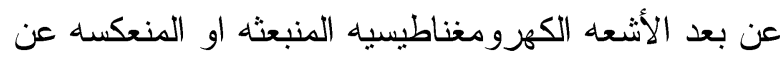

$$
\begin{aligned}
& \text { الظو اهر الأرضيه المختلفه التى تقع ضمن زاويه تصوير } \\
& \text { كو اشف الأقمار الصناعيه و تتأثز تلك الأشعه } \\
& \text { الكهرومغناطيسيه بتاثير ات الأضطر ابات الجويه خلأل }
\end{aligned}
$$

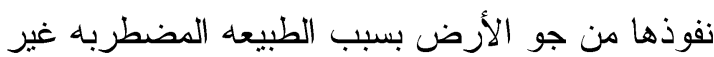

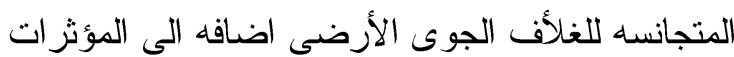

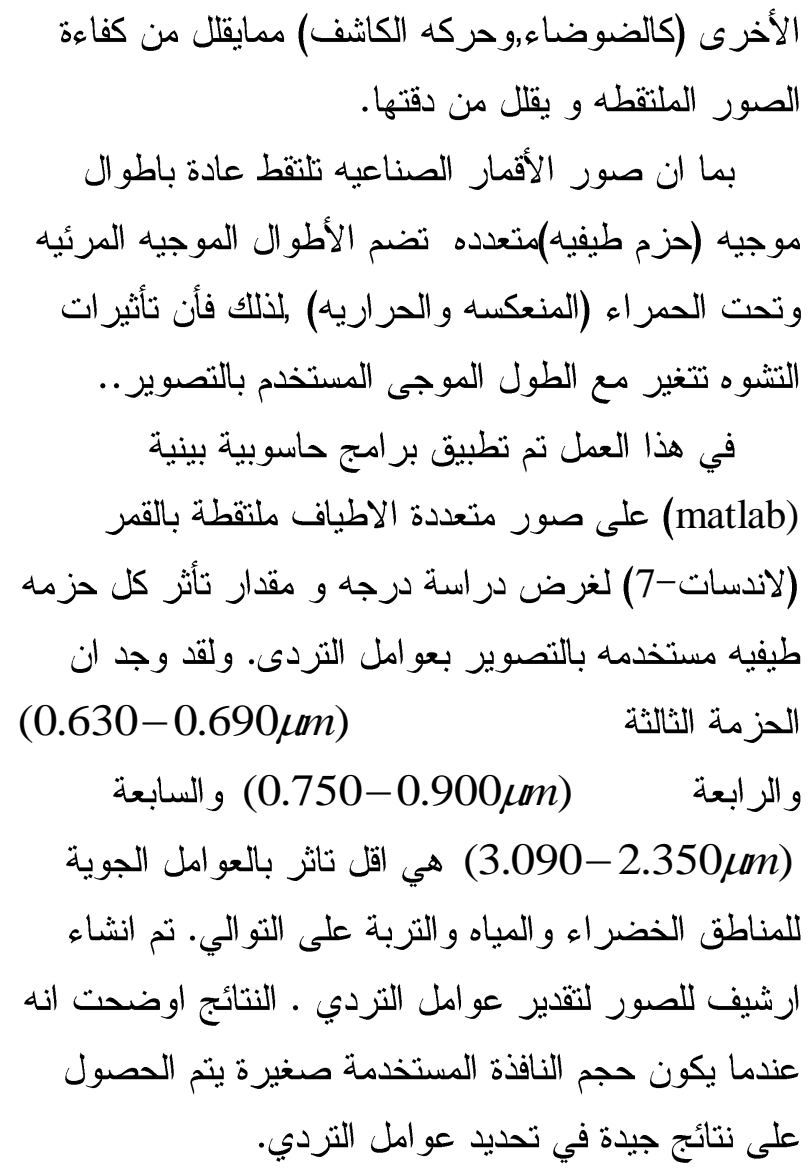

